Inhalt

1. Kapitel

Einführung und historische Aspekte . . . . . . 10

\title{
2. Kapitel
}

Das Sterben aus medizinischer Sicht . . . . . . 21

2.1. Einige Ursachen des zunehmenden Interesses an der Sterbeproblematik . . . . . . . . . . . . 21

2.2. Das Sterben aus medizinischer Sicht . . . . . . 27

2.3. Die Definition des Sterbens . . . . . . . . . 28

2.4. Das prozeßhafte Sterben eines vitalen Organs . . 29

2.5. Der Arzt und der sterbende Mensch . . . . . . 36

2.6. Die verschiedenen Formen des Sterbens . . . . 39

2.6.1. Das altersbedingte Sterben . . . . . . . . . . 40

2.6.2. Das Sterben an einer prognostisch infausten Erkrankung . . . . . . . . . . . . . . . . . 49

2.6.3. Das akute, krankheitsbedingte oder durch äußere Gewalt verursachte Sterben. . . . . . . . . 52

2.6.4. Das postreanimative Phänomen . . . . . . . . 54

2.7. Phasen-Einteilung des Sterbens . . . . . . . 57

\section{Kapitel}

Medizinische Methoden zur Abwendung des Sterbens . . . . . . . . . . . . . . 68

3.1. Die Reanimatologie . . . . . . . . . . . . . 68

3.2. Die Indikation für eine Reanimation . . . . . 81

3.3. Die gegenwärtigen Grenzen der Reanimation . . 85 
3.4. Die Reanimation und der Ersatz eines vitalen Organs . . . . . . . . . . . . . 95

3.5. Die Reanimation - im Interesse des Patienten? 119

3.6. Die Intensivmedizin im Grenzbereich zwischen Leben und Tod . . . . . . . . . . . . . . 126

3.7. Die Grenzen der Intensivmedizin . . . . . . . 133

4. Kapitel

Sterben und Tod in der modernen Medizin . . 144

4.1. Definitionen des Todes . . . . . . . . . . . 144

4.2. Der prozeßhafte Ablauf des Todes . . . . . . 148

4.3. Der Hirntod . . . . . . . . . . . . . . . . . 154

4.4. Der Hirntod und die Organextransplantation . . 164

4.5. Der verdrängte Tod . . . . . . . . . . . . . 169

Literatur . . . . . . . . . . . . . . . 177

Glossar . . . . . . . . . . . . 186 